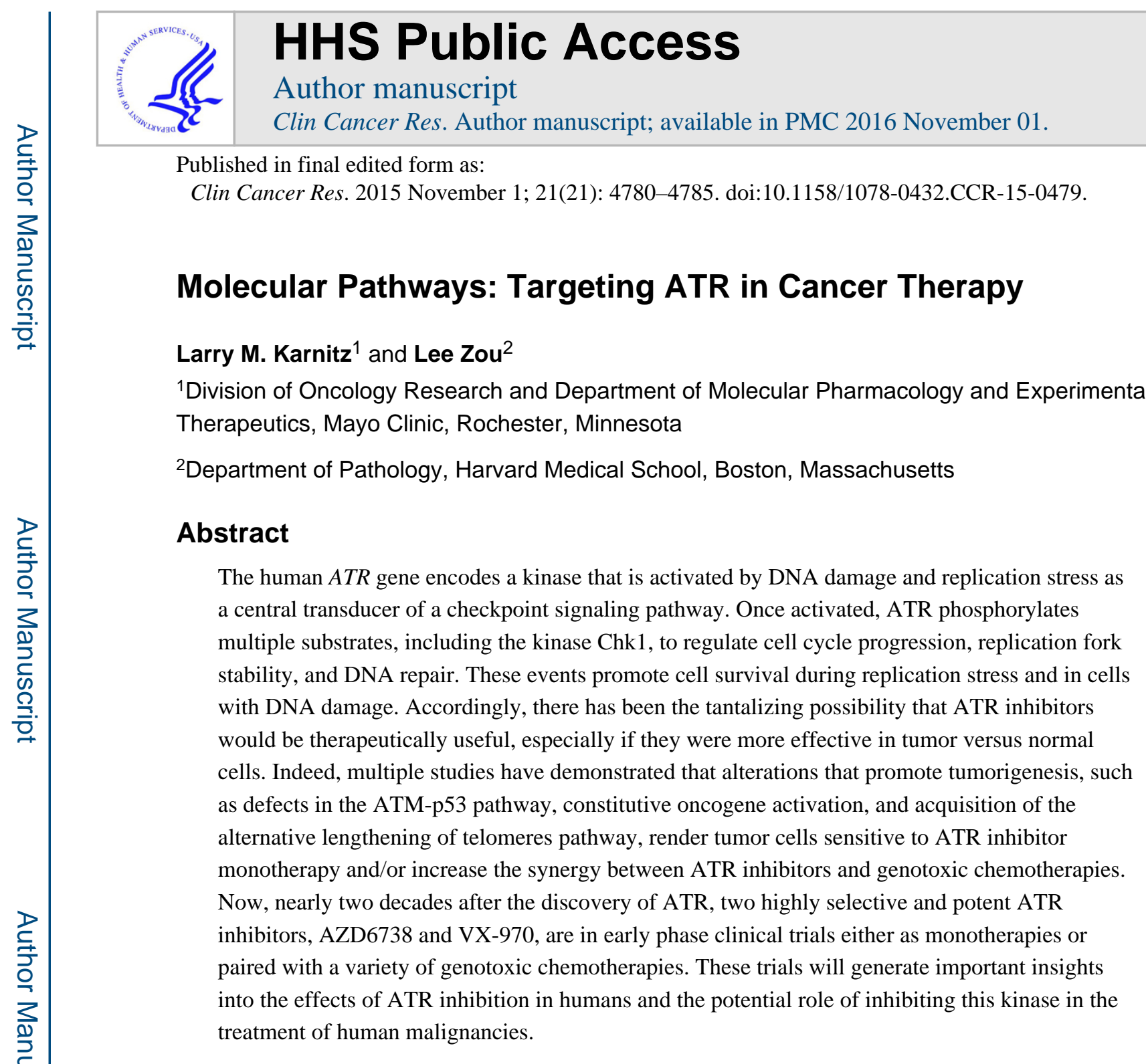

\title{
Background
}

The ATR-Chk1 pathway

\begin{abstract}
ATM (ataxia telangiectasia mutated) and ATR (ATM and rad3-related) kinases are two master regulators of DNA damage responses in human cells (1). These two PI3K-like protein kinases have overlapping and also distinct functions. Whereas ATM is primarily involved in the response to DNA double-stranded breaks (DSBs), ATR responds to a wide range of DNA damage and DNA replication problems. When activated by DNA damage or replication stress, ATR phosphorylates and activates its effector kinase Chk1 (1, 2) (Fig. 1). The ATR-Chk1 pathway protects the genome against DNA damage and replication stress by
\end{abstract}

\footnotetext{
Corresponding Author: Larry M. Karnitz, Mayo Clinic, 200 First Street SW, Gonda 19-300, Rochester, MN 55905. Phone: 507-284-3124; Fax: 507-293-0107; Karnitz.larry@ mayo.edu.

Disclosure of Potential Conflicts of Interest

No potential conflicts of interest were disclosed.

Authors' Contributions

Conception and design: L.M. Karnitz, L. Zou

Writing, review and/or revision of manuscript: L.M. Karnitz, L. Zou
} 
regulating and coordinating multiple cellular processes, which include but are not limited to cell cycle arrest, inhibition of replication origin firing, protection of stressed replication forks, and DNA repair.

The activation of the ATR-Chk1 pathway is triggered by RPA-coated single-stranded DNA (ssDNA), a nucleoprotein structure commonly generated at sites of DNA damage and stressed replication forks $(1,2)$. ATRIP, the regulatory partner of ATR, directly binds RPA, thereby allowing the ATR-ATRIP complex to recognize the RPA-ssDNA at DNA damage sites or stressed replication forks (3). Several other regulators of ATR, including the Rad17 complex, the Rad9-Rad1-Hus1 (9-1-1) complex, and RIHNO, are recruited to junctions of RPA-ssDNA and double-stranded DNA (dsDNA) (1). Together, these proteins enable TopBP1 to stimulate the kinase activity of ATR-ATRIP. With the help of mediator proteins such as Claspin, ATR recognizes and phosphorylates Chk1, leading to activation of the ATR-Chk1 pathway.

A growing list of DNA replication, DNA repair, and cell cycle proteins have been shown to be substrates and effectors of ATR and Chk1. For example, the phosphorylation of Cdc25 phosphatases by Chk1 is important for DNA damage-induced cell cycle arrest (4). The phosphorylation of WRN, SMARCAL1, and FANCI by ATR is important for proper DNA replication in cells under replication stress (5-7). ATR also regulates several DNA repair pathways, such as homologous recombination, DNA interstrand crosslink repair, and nucleotide excision repair (8-10). Importantly, the ATR-Chk1 pathway not only responds to extrinsic DNA damage and replication stress, but also to intrinsic problems such as those induced by oncogenic events (11). These properties of the ATR-Chk1 pathway have made it an attractive target for therapeutic intervention.

\section{Role of the ATR-Chk1 pathway in cancer}

ATR is important for cell survival; in mouse models, homozygous ATR inactivation is embryonically lethal, and mouse embryonic fibroblasts in which ATR is acutely genetically inactivated undergo one or two rounds of DNA replication before permanently exiting the cell cycle (12). The ATR pathway is likely essential due to the replication stress that is caused by spontaneous DNA damage and difficult-to-replicate regions of the genome such as fragile sites. Similarly, genetic inactivation of ATR in adult mouse tissues causes premature aging, defects in tissue homeostasis, and depletion of progenitor cells in rapidly proliferating tissues $(13,14)$. Notably, however, partially disabling ATR signaling is compatible with life. In humans with Seckel syndrome and in a mouse model of this syndrome, ATR levels are severely reduced due to a homozygous mutation that induces an mRNA splicing defect (15). Similarly, in a hypomorphic mouse model that reduces ATR levels to $10 \%$ of normal, these mice were remarkably normal with no defects even in highly proliferative tissues (16).

In many tumor cells, however, ATR appears to be even more important than it is in normal cells. First, the dysregulated signaling induced by some oncoproteins, such as the Ras isoforms, Myc, and Cyclin E disrupts normal cell cycle regulation and causes replication stress (17). Indeed, in such tumor cells, the ATR pathway is critical for survival, and multiple studies have shown that inhibiting this pathway is selectively toxic in cells with 
high levels of oncogene-induced replication stress $(16,18-24)$. Second, ATM deficiency renders cells far more sensitive to ATR inhibition in cell culture and in animal models (2527), a finding that has led to clinical trials of an ATR inhibitor in tumors characterized by ATM deficiency or ATM mutations (see below). Third, loss of specific DNA repair proteins (e.g., XRCC1, ERCC1) also causes tumor cell lines to be more sensitive to ATR inhibition, at least in cell line models (28-31); however, these findings have not yet been extended to animal models. Third, hypoxic cells, which are typically resistant to chemo- and radiation therapy (32), are sensitive to ATR inhibition (33-35), likely because hypoxia causes replication stress (36). Fourth, tumor cells that rely on the alternative lengthening of telomeres (ALT) pathway are also more sensitive to ATR disruption due to ATR's role in the homologous recombination reactions that maintain these telomeres (37). Taken together, these observations indicate that multiple events that drive tumorigenesis may create a synthetic lethality for ATR inhibition similar to the finding that PARP inhibition is synthetically lethality in BRCA1/2-deficient tumors (38).

Notably, however, the potential for ATR inhibitors extends well beyond tumors with these phenotypes. ATR promotes cell survival by blocking cell cycle progression, stabilizing stalled replication forks, and facilitating DNA repair, including homologous recombination. As such, even in cells in which disabling/inhibiting ATR has limited (or no) cytotoxic activity, ATR inhibitors robustly sensitize to or synergize with nearly all genotoxic therapies that have been tested. One major concern with any agent that increases the cytotoxic activity of a genotoxin is the potential for similar sensitization or synergy in normal cells. That concern has been eased by the findings to date. Multiple studies have shown that ATR inhibitors more effectively synergize with genotoxins in cell with defects in the p53 pathway than in p53-proficient cells $(20,25,27,31,39)$, possibly due to the loss of the G1 checkpoint and/or increased replication stress that occurs due to relaxed S-phase entry (17). These findings thus suggest that there may be a therapeutic index for ATR inhibitors in the clinic in tumors with defects in the p53 pathway.

\section{Clinical-Translational Advances}

\section{ATR inhibitors}

ATR is a member of the phosphatidylinositol 3-kinase (PI3K)-related kinase (PIKK) family, which also includes ATM, mTOR, DNA-PKcs, SMG1, and PI3K. The first identified ATR inhibitor was caffeine, which disrupts DNA damage-induced cell cycle arrest and sensitizes cells to DNA damage $(40,41)$. However, this agent also inhibits ATM and other members of the PI3K family, and cannot be used clinically since concentrations that inhibit ATR and ATM are toxic.

Due to the atypical nature of the PIKKs, identification of potent and selective inhibitors for this family of kinases lagged the development of inhibitors for more conventional serine, threonine, and tyrosine kinases. Early screening studies identified schisandrin B as a weak ATR inhibitor with more specificity than caffeine. More recently, NU6027, NVP-BEZ235, torin 2, and ETP-46464 were reported as more potent ATR inhibitors that sensitized tumor cells to a variety of genotoxic chemotherapies, but they also inhibited other kinases such as CDK2, PIK3, mTOR, and ATM (42).

Clin Cancer Res. Author manuscript; available in PMC 2016 November 01. 
In 2011, the first potent and selective inhibitor, VE-821, was reported by Vertex Pharmaceuticals. VE-821 has >100-fold selectivity for ATR versus ATM, PI3K, DNA-PK, mTOR (43), and its analog VE-822 (VX-970) has been further improved with increased solubility, potency, selectivity, and pharmacodynamic properties $(25,44)$. Preclinical studies have shown that these agents robustly sensitize multiple tumor cell lines to cisplatin, ionizing radiation, gemcitabine, PARP inhibitors, topoisomerase I poisons, etoposide, and oxaliplatin in vitro $(34,35,45-50)$. In xenograft studies, VE-821 and VX-970 have shown impressive results. VE-821 and VX-970 synergized with radiation and gemcitabine in pancreatic cancer xenograft models $(35,45)$ and with irinotecan in a colorectal cancer model (48). Similarly, VX-970 sensitized six of seven patient-derived primary lung tumor xenograft models to cisplatin, even sensitizing cisplatin-resistant tumors to cisplatin (49). Importantly, the addition of VE-821 or VX970 did not exacerbate the general toxicity of the genotoxic therapies.

AstraZeneca has also developed highly selective and potent ATR inhibitors. AZ20 was first reported in 2103 (26). AZ20's analog, AZD6738, an orally available agent with better solubility and pharmacodynamic properties, was reported in 2013 (51). AZD6738 has excellent selectivity for ATR versus the other PIKKs and other kinases (52). Both compounds show single-agent activity in p53- and ATM-deficient tumor models and sensitize to or synergize with gemcitabine, cisplatin, ionizing radiation, and PARP inhibition in vitro $(29,30,51-53)$. In xenograft models, AZD6738 has activity as a monotherapy in xenografts of ATM- and p53-deficient mantle cell lymphoma cell line (54) and in primary CLL patient-derived xenografts with 11q deletion (ATM-deficient) and 17p deletion (p53deficient) (53). AZD6738 also synergizes with carboplatin, bendamustine, and cyclophosphamide in an ATM-deficient diffuse large B-cell lymphoma model (52), and with a PARP inhibitor in a primary triple negative breast cancer explant where neither AZD6738 nor the PARP inhibitor had antitumor activity as single agents (52).

\section{ATR inhibitors in clinical trials}

Two selective and potent ATR inhibitors are currently in Phase I/II clinical trials. The first to enter the clinic was VX-970. This agent, which is administered intravenously, is being studied in combination with cisplatin, gemcitabine/cisplatin, and etoposide/cisplatin in advanced solid tumors to identify maximum tolerated doses (MTD) and determine optimal dosing schedules (clinicaltrials.gov NCT02157792 and clinicaltrialsregister.eu 2012-003126-25). Planned expansion studies in this trial will examine VX-970 in combination with 1) gemcitabine/cisplatin in advanced squamous nonsmall cell lung cancer, 2) cisplatin in triple negative breast cancer with or without BRCA1/2 mutations, and 3) cisplatin/etoposide in relapsed/refractory small cell lung cancer. The rationale for targeting these diseases is that these tumors respond to these genotoxic therapies, thus raising the possibility that VX-970 with increase the response rates and progression-free and overall survival. A second VX-970 trial is assessing VX-970 as a single agent and in combination carboplatin in triple negative breast cancer and high-grade serous ovarian cancer (clinicaltrialsregister.eu 2013-005100-34), two tumors that frequently have defects in homologous recombination (55).

Clin Cancer Res. Author manuscript; available in PMC 2016 November 01. 
Unlike VX-970, AZD6738 can be dosed orally. Three clinical trials have been initiated with AZD6738. One trial, which has been completed but not yet reported, was based on the observation that ATM deficiency is synthetic lethal with ATR inhibition. Accordingly, this trial focused on patients with ATM-deficient chronic lymphocytic leukemia, which frequently lacks functions ATM due to deletions in 11q and other ATM mutations (clinicaltrials.gov NCT01955668). For the trials that are underway, one is identifying the maximum tolerated dose for AZD6738 in combination with radiotherapy in patients with head and neck cancers and abdominal and pelvic cancers that are typically treated with radiotherapy (clinicaltrials.gov NCT02223923). The second ongoing trial is also targeting tumors with defects that likely confer sensitivity to ATR inhibition but in combination with chemotherapy agents (clinicaltrials.gov NCT02264678). This Phase I/II trial is examining AZD6738 in combination with carboplatin by first identifying the maximum tolerated dose of the combination and then assessing the combination in two expansion cohorts: 1) in ATM-deficient advanced lung adenocarcinomas $(56,57), 2)$ and in high-grade serous ovarian cancers, which have frequent defects in homologous recombination due to mutations in BRCA1/2 and other genes that encode homologous recombination participants (58). Interestingly, another part of this trial will also identify the MTD of AZD6738 in combination with the PARP inhibitor olaparib and then examine this combination in gastric cancers with low ATM expression, a frequent occurrence due to ATM mutations in this malignancy (59). This trial is particularly interesting based on the observations that 1) ATM is frequently mutated in this cancer, 2) disabling ATM sensitizes tumor cells to ATR and PARP inhibition, and 3) ATR inhibition sensitizes to PARP inhibition even in cells with intact homologous recombination $(30,31,46)$.

\section{Open Questions}

Despite the exciting preclinical data and progress in moving ATR inhibitors into the clinic, significant questions remain.

ATR versus Chk1 inhibition-Because ATR and Chk1 are in the same pathway, it is possible that the antitumor activities of ATR inhibitors may not differ significantly from Chk1 inhibitors, which are currently in clinical trials. While this is possible, it seems unlikely because ATR has many substrates other than Chk1, thus suggesting that it controls additional cell responses. Consistent with this idea are recent studies showing that ATR inhibition sensitizes to a wider range of chemotherapy agents in most cell lines $(46,60,61)$. Accordingly, ATR inhibitors may have broader clinical utility than Chk1 inhibitors.

Predictive biomarkers-Preclinical studies have identified a series of tumor-specific alterations that affect sensitivity to ATR inhibition. As such, these alterations may be potential biomarkers to predict tumor responses to ATR inhibitor monotherapy and combination therapies. The best validated biomarkers are defects in ATM and p53 pathways. Strong preclinical data, including animal models using ATM-deficient primary patient-derived CLL neoplasms (53), show that ATM deficiency is synthetically lethal with ATR inhibition. Similarly, p53-deficient cell lines are much more sensitive to ATR inhibitor plus genotoxin combinations than are p53-proficient cell lines (20), although ATR inhibitor sensitize to genotoxins even in some primary tumors with wild-type p53 (49). Other 
potential predictive biomarkers include the genes that encode Myc, the Ras isoforms, and Cyclin E. Overexpression or constitutive activation of these oncogenes dysregulates cell cycle progression and generates replication stress, thus making these tumors hyper-reliant on the ATR-Chk1 pathway(11). Finally, tumor hypoxia, XRCC1 and ERCC1 deficiencies, and reliance on the ALT pathway also render cells more sensitive to ATR inhibition (28-31, 34, 37), although these potential biomarkers have not yet been as extensively examined and whether they affect responses in animal models is not known.

Toxicity of ATR inhibition-Because ATR is critical for the survival of normal cells in some contexts, it was initially unclear whether ATR would be a viable therapeutic target. However, the observations that severely reduced ATR levels in mice were compatible with viability suggested that ATR inhibition might be tolerated. Indeed, multiple mouse studies have now established that ATR inhibitors are not severely toxic, likely because inhibition is neither continuous nor complete. Importantly, these studies showed that ATR inhibition did not worsen the toxic effects of multiple genotoxic agents (similar to the findings with the potent and selective Chk1 inhibitor MK-8776 in human clinical trials), while still synergizing with genotoxic therapies. Accordingly, these findings suggest that there is a therapeutic window, likely due to the increased reliance of tumor cells on the ATR pathway because of oncogene-induced replication stress and/or disabled ATM-p53 signaling. Nonetheless, despite these positive outcomes, toxicity issues remain a concern. For example, Clack et al observed that AZD6738 dosing before carboplatin was tolerable in an animal model, whereas the reverse sequence was not (52). Furthermore, there have been no assessments of long-term toxicities. Because the DNA damage pathway is a barrier to tumorigenesis $(62,63)$, it is possible that disabling this pathway while administering genotoxins may increase the risk of second cancers due to the potential genome destabilizing effects of such a combination. However, it is also possible that reduced ATR signaling may actually prevent tumorigenesis; indeed, reduced ATR levels limit tumorigenesis in several mouse models of cancer $(16,19,64)$. The clinical trials that are currently underway will determine whether ATR inhibition in monotherapy and combination therapy settings has acceptable short-term toxicity.

\section{Timing of ATR inhibition with respect to genotoxin delivery-A major} unanswered question is how to sequence the delivery of an ATR inhibitor with respect to a genotoxic chemotherapeutic during combination therapy. One the one hand, it seems logical to have ATR suppressed during and after genotoxin exposure, and strong synergy is observed in cultured cells treated in this way. However, studies with a Chk1 inhibitor in cultured cells and in an animal model showed that adding the inhibitor 24 hours after exposure to gemcitabine led to more synergism than other sequencing strategies (e.g., simultaneous addition, or adding the Chk1 inhibitor first), thus suggesting that delayed inhibition might increase synergy $(65,66)$. We are not aware of similar sequencing studies with ATR inhibitors in cell lines. The problem becomes even more complex when considering the timing of ATR inhibitor dosing with respect to the genotoxin in animal models and humans. Under these conditions it is unclear when maximal genotoxin-induced DNA damage in the tumor has occurred and whether the ATR inhibitor can be delivered over long or short intervals with acceptable toxicity. 
Since the discovery that the ATR-Chk1 pathway promoted the survival of tumor cells exposed to DNA damaging agents and replication stress, there has been hope that small molecule inhibitors of this pathway would increase the efficacy of chemotherapy agents that can, in some cases, cure human cancers. With the development of highly specific ATR inhibitors, we are now poised to determine if disabling ATR will have therapeutic benefit. We look forward to the results of these trials and the additional questions they will almost certainly raise.

\section{Acknowledgments}

\section{Grant Support}

Research reported in this publication was supported in part by the NIH under award numbers P50CA136393 to L.M. Karnitz and GM076388 to L. Zou. L. Zou is a Jim \& Ann Orr Massachusetts General Hospital Research Scholar.

\section{References}

1. Marechal A, Zou L. DNA damage sensing by the ATM and ATR kinases. Cold Spring Harb Perspect Biol. 2013; 5:a012716. [PubMed: 24003211]

2. Zeman MK, Cimprich KA. Causes and consequences of replication stress. Nat Cell Biol. 2014; 16:2-9. [PubMed: 24366029]

3. Zou L, Elledge SJ. Sensing DNA damage through ATRIP recognition of RPA-ssDNA complexes. Science. 2003; 300:1542-1548. [PubMed: 12791985]

4. Lam MH, Rosen JM. Chk1 versus Cdc25: chking one's levels of cellular proliferation. Cell Cycle. 2004; 3:1355-1357. [PubMed: 15483403]

5. Ammazzalorso F, Pirzio LM, Bignami M, Franchitto A, Pichierri P. ATR and ATM differently regulate WRN to prevent DSBs at stalled replication forks and promote replication fork recovery. Embo J. 2010; 29:3156-3169. [PubMed: 20802463]

6. Couch FB, Bansbach CE, Driscoll R, Luzwick JW, Glick GG, Betous R, et al. ATR phosphorylates SMARCAL1 to prevent replication fork collapse. Genes Dev. 2013; 27:1610-1623. [PubMed: 23873943]

7. Chen YH, Jones MJ, Yin Y, Crist SB, Colnaghi L, Sims RJ 3rd, et al. ATR-mediated phosphorylation of FANCI regulates dormant origin firing in response to replication stress. Mol Cell. 2015; 58:323-338. [PubMed: 25843623]

8. Wang H, Wang H, Powell SN, Iliakis G, Wang Y. ATR affecting cell radiosensitivity is dependent on homologous recombination repair but independent of nonhomologous end joining. Cancer Res. 2004; 64:7139-7143. [PubMed: 15466211]

9. Andreassen PR, D'Andrea AD, Taniguchi T. ATR couples FANCD2 monoubiquitination to the DNA-damage response. Genes Dev. 2004; 18:1958-1963. [PubMed: 15314022]

10. Wu X, Shell SM, Liu Y, Zou Y. ATR-dependent checkpoint modulates XPA nuclear import in response to UV irradiation. Oncogene. 2007; 26:757-764. [PubMed: 16862173]

11. Lecona E, Fernandez-Capetillo O. Replication stress and cancer: it takes two to tango. Exp Cell Res. 2014; 329:26-34. [PubMed: 25257608]

12. Cimprich KA, Cortez D. ATR: an essential regulator of genome integrity. Nat Rev Mol Cell Biol. 2008; 9:616-627. [PubMed: 18594563]

13. Ruzankina Y, Pinzon-Guzman C, Asare A, Ong T, Pontano L, Cotsarelis G, et al. Deletion of the developmentally essential gene ATR in adult mice leads to age-related phenotypes and stem cell loss. Cell Stem Cell. 2007; 1:113-126. [PubMed: 18371340]

14. Brown EJ, Baltimore D. Essential and dispensible roles of ATR in cell cycle arrest and genome maintenance. Genes and Dev. 2003; 17:615-628. [PubMed: 12629044]

Clin Cancer Res. Author manuscript; available in PMC 2016 November 01. 
15. O'Driscoll M, Ruiz-Perez VL, Woods CG, Jeggo PA, Goodship JA. A splicing mutation affecting expression of ataxia-telangiectasia and Rad3-related protein (ATR) results in Seckel syndrome. Nat Genet. 2003; 33:497-501. [PubMed: 12640452]

16. Schoppy DW, Ragland RL, Gilad O, Shastri N, Peters AA, Murga M, et al. Oncogenic stress sensitizes murine cancers to hypomorphic suppression of ATR. J Clin Invest. 2012; 122:241-252. [PubMed: 22133876]

17. Toledo LI, Murga M, Fernandez-Capetillo O. Targeting ATR and Chk1 kinases for cancer treatment: a new model for new (and old) drugs. Mol Oncol. 2011; 5:368-373. [PubMed: 21820372]

18. Hoglund A, Nilsson LM, Muralidharan SV, Hasvold LA, Merta P, Rudelius M, et al. Therapeutic implications for the induced levels of Chk1 in Myc-expressing cancer cells. Clin Cancer Res. 2011; 17:7067-7079. [PubMed: 21933891]

19. Murga M, Campaner S, Lopez-Contreras AJ, Toledo LI, Soria R, Montana MF, et al. Exploiting oncogene-induced replicative stress for the selective killing of Myc-driven tumors. Nat Struct Mol Biol. 2011; 18:1331-1335. [PubMed: 22120667]

20. Toledo LI, Murga M, Zur R, Soria R, Rodriguez A, Martinez S, et al. A cell-based screen identifies ATR inhibitors with synthetic lethal properties for cancer-associated mutations. Nat Struct Mol Biol. 2011; 18:721-727. [PubMed: 21552262]

21. Gilad O, Nabet BY, Ragland RL, Schoppy DW, Smith KD, Durham AC, et al. Combining ATR suppression with oncogenic Ras synergistically increases genomic instability, causing synthetic lethality or tumorigenesis in a dosage-dependent manner. Cancer Res. 2010; 70:9693-9702. [PubMed: 21098704]

22. Ferrao PT, Bukczynska EP, Johnstone RW, McArthur GA. Efficacy of CHK inhibitors as single agents in MYC-driven lymphoma cells. Oncogene. 2012; 31:1661-1672. [PubMed: 21841818]

23. Walton MI, Eve PD, Hayes A, Valenti MR, De Haven Brandon AK, Box G, et al. CCT244747 is a novel potent and selective CHK1 inhibitor with oral efficacy alone and in combination with genotoxic anticancer drugs. Clin Cancer Res. 2012; 18:5650-5661. [PubMed: 22929806]

24. Cole KA, Huggins J, Laquaglia M, Hulderman CE, Russell MR, Bosse K, et al. RNAi screen of the protein kinome identifies checkpoint kinase 1 (CHK1) as a therapeutic target in neuroblastoma. Proc Natl Acad Sci U S A. 2011; 108:3336-3341. [PubMed: 21289283]

25. Fokas E, Prevo R, Hammond EM, Brunner TB, McKenna WG, Muschel RJ. Targeting ATR in DNA damage response and cancer therapeutics. Cancer Treat Rev. 2014; 40:109-117. [PubMed: 23583268]

26. Foote KM, Blades K, Cronin A, Fillery S, Guichard SS, Hassall L, et al. Discovery of 4-\{4[(3R)-3-Methylmorpholin-4-yl]-6-[1-(methylsulfonyl)cyclopropyl]pyrimidin-2-y 1\}-1H-indole (AZ20): a potent and selective inhibitor of ATR protein kinase with monotherapy in vivo antitumor activity. J Med Chem. 2013; 56:2125-2138. [PubMed: 23394205]

27. Reaper PM, Griffiths MR, Long JM, Charrier JD, Maccormick S, Charlton PA, et al. Selective killing of ATM- or p53-deficient cancer cells through inhibition of ATR. Nat Chem Biol. 2011; 7:428-430. [PubMed: 21490603]

28. Sultana R, Abdel-Fatah T, Perry C, Moseley P, Albarakti N, Mohan V, et al. Ataxia telangiectasia mutated and Rad3 related (ATR) protein kinase inhibition is synthetically lethal in XRCC1 deficient ovarian cancer cells. PLoS One. 2013; 8:e57098. [PubMed: 23451157]

29. Mohni KN, Kavanaugh GM, Cortez D. ATR pathway inhibition is synthetically lethal in cancer cells with ERCC1 deficiency. Cancer Res. 2014; 74:2835-2845. [PubMed: 24662920]

30. Mohni KN, Thompson PS, Luzwick JW, Glick GG, Pendleton CS, Lehmann BD, et al. A synthetic lethal screen identifies DNA repair pathways that sensitize cancer cells to combined ATR inhibition and cisplatin treatments. PLoS One. 2015; 10:e0125482. [PubMed: 25965342]

31. Peasland A, Wang LZ, Rowling E, Kyle S, Chen T, Hopkins A, et al. Identification and evaluation of a potent novel ATR inhibitor, NU6027, in breast and ovarian cancer cell lines. Br J Cancer. 2011; 105:372-381. [PubMed: 21730979]

32. Bristow RG, Hill RP. Hypoxia and metabolism. Hypoxia, DNA repair and genetic instability. Nat Rev Cancer. 2008; 8:180-192. [PubMed: 18273037]

Clin Cancer Res. Author manuscript; available in PMC 2016 November 01. 
33. Hammond EM, Dorie MJ, Giaccia AJ. Inhibition of ATR leads to increased sensitivity to hypoxia/ reoxygenation. Cancer Res. 2004; 64:6556-6562. [PubMed: 15374968]

34. Pires IM, Olcina MM, Anbalagan S, Pollard JR, Reaper PM, Charlton PA, et al. Targeting radiation-resistant hypoxic tumour cells through ATR inhibition. Br J Cancer. 2012; 107:291-299. [PubMed: 22713662]

35. Prevo R, Fokas E, Reaper PM, Charlton PA, Pollard JR, McKenna WG, et al. The novel ATR inhibitor VE-821 increases sensitivity of pancreatic cancer cells to radiation and chemotherapy. Cancer Biol Ther. 2012; 13:1072-1081. [PubMed: 22825331]

36. Pires IM, Bencokova Z, Milani M, Folkes LK, Li JL, Stratford MR, et al. Effects of acute versus chronic hypoxia on DNA damage responses and genomic instability. Cancer Res. 2010; 70:925935. [PubMed: 20103649]

37. Flynn RL, Cox KE, Jeitany M, Wakimoto H, Bryll AR, Ganem NJ, et al. Alternative lengthening of telomeres renders cancer cells hypersensitive to ATR inhibitors. Science. 2015; 347:273-277. [PubMed: 25593184]

38. Scott CL, Swisher EM, Kaufmann SH. Poly (ADP-ribose) polymerase inhibitors: recent advances and future development. J Clin Oncol. 2015; 33:1397-1406. [PubMed: 25779564]

39. Nghiem P, Park PK, Kim Y, Vaziri C, Schreiber SL. ATR inhibition selectively sensitizes G1 checkpoint-deficient cells to lethal premature chromatin condensation. Proc Natl Acad Sci U S A. 2001; 98:9092-9097. [PubMed: 11481475]

40. Sarkaria JN, Busby EC, Tibbetts RS, Roos P, Taya Y, Karnitz LM, et al. Inhibition of ATM and ATR kinase activities by the radiosensitizing agent, caffeine. Cancer Res. 1999; 59:4375-4382. [PubMed: 10485486]

41. Blasina A, Price BD, Turenne GA, McGowan CH. Caffeine inhibits the checkpoint kinase ATM. Current Biology. 1999; 9:1135-1138. [PubMed: 10531013]

42. Weber AM, Ryan AJ. ATM and ATR as therapeutic targets in cancer. Pharmacol Ther. 2015; 149:124-138. [PubMed: 25512053]

43. Charrier JD, Durrant SJ, Golec JM, Kay DP, Knegtel RM, MacCormick S, et al. Discovery of potent and selective inhibitors of ataxia telangiectasia mutated and Rad3 related (ATR) protein kinase as potential anticancer agents. J Med Chem. 2011; 54:2320-2330. [PubMed: 21413798]

44. Asmal M, Dean E, Evans J, Middleton M, Plummer R. VX-970, selective inhibitor of ataxia telangiectasia and Rad3-related (ATR) protein [abstract]. Ann Oncol. 2015; 26(Suppl 2):ii8. Abstract nr. O6.4.

45. Fokas E, Prevo R, Pollard JR, Reaper PM, Charlton PA, Cornelissen B, et al. Targeting ATR in vivo using the novel inhibitor VE-822 results in selective sensitization of pancreatic tumors to radiation. Cell Death Dis. 2012; 3:e441. [PubMed: 23222511]

46. Huntoon CJ, Flatten KS, Wahner Hendrickson AE, Huehls AM, Sutor SL, Kaufmann SH, et al. ATR inhibition broadly sensitizes ovarian cancer cells to chemotherapy independent of BRCA status. Cancer Res. 2013; 73:3683-3691. [PubMed: 23548269]

47. Vavrova J, Zarybnicka L, Lukasova E, Rezacova M, Novotna E, Sinkorova Z, et al. Inhibition of ATR kinase with the selective inhibitor VE-821 results in radiosensitization of cells of promyelocytic leukaemia (HL-60). Radiat Environ Biophys. 2013; 52:471-479. [PubMed: 23934411]

48. Josse R, Martin SE, Guha R, Ormanoglu P, Pfister TD, Reaper PM, et al. The ATR inhibitors VE-821 and VX-970 sensitize cancer cells to topoisomerase I inhibitors by disabling DNA replication initiation and fork elongation responses. Cancer Res. 2014; 74:6968-6979. [PubMed: 25269479]

49. Hall AB, Newsome D, Wang Y, Boucher DM, Eustace B, Gu Y, et al. Potentiation of tumor responses to DNA damaging therapy by the selective ATR inhibitor VX-970. Oncotarget. 2014; 5:5674-5685. [PubMed: 25010037]

50. Abdel-Fatah TM, Middleton FK, Arora A, Agarwal D, Chen T, Moseley PM, et al. Untangling the ATR-CHEK1 network for prognostication, prediction and therapeutic target validation in breast cancer. Mol Oncol. 2015; 9:569-585. [PubMed: 25468710]

Clin Cancer Res. Author manuscript; available in PMC 2016 November 01. 
51. Jones CD, Blades K, Foote KM, Guichard SM, Jewsbury PJ, McGuire T, et al. Abstract 2348: Discovery of AZD6738, a potent and selective inhibitor with the potential to test the clinical efficacy of ATR kinase inhibition in cancer patients. Cancer Res. 2013; 73:2348.

52. Clack G, Lau A, Pierce A, Smith S, Stephens C. ATR inhibitor AZD6738 [abstract]. Ann Oncol. 2015; 26(Suppl 2):ii8. Abstract nr. O6.3.

53. Kwok M, Davies N, Agathanggelou A, Smith E, Petermann E, Yates E, et al. Synthetic lethality in chronic lymphocytic leukaemia with DNA damage response defects by targeting the ATR pathway. Lancet. 2015; 385(Suppl 1):S58. [PubMed: 26312880]

54. Menezes DL, Holt J, Tang Y, Feng J, Barsanti P, Pan Y, et al. A synthetic lethal screen reveals enhanced sensitivity to ATR inhibitor treatment in mantle cell lymphoma with ATM loss-offunction. Mol Cancer Res. 2015; 13:120-129. [PubMed: 25232030]

55. Krajewska M, Fehrmann RS, de Vries EG, van Vugt MA. Regulators of homologous recombination repair as novel targets for cancer treatment. Front Genet. 2015; 6:96. [PubMed: 25852742]

56. Ding L, Getz G, Wheeler DA, Mardis ER, McLellan MD, Cibulskis K, et al. Somatic mutations affect key pathways in lung adenocarcinoma. Nature. 2008; 455:1069-1075. [PubMed: 18948947]

57. Cancer Genome Atlas Research Network. Comprehensive molecular profiling of lung adenocarcinoma. Nature. 2014; 511:543-550. [PubMed: 25079552]

58. Cancer Genome Atlas Research Network. Integrated genomic analyses of ovarian carcinoma. Nature. 2011; 474:609-615. [PubMed: 21720365]

59. Cancer Genome Atlas Research N. Comprehensive molecular characterization of gastric adenocarcinoma. Nature. 2014; 513:202-209. [PubMed: 25079317]

60. Xiao Y, Ramiscal J, Kowanetz K, Del Nagro C, Malek S, Evangelista M, et al. Identification of preferred chemotherapeutics for combining with a CHK1 inhibitor. Mol Cancer Ther. 2013; 12:2285-2295. [PubMed: 24038068]

61. Montano R, Chung I, Garner KM, Parry D, Eastman A. Preclinical development of the novel Chk1 inhibitor SCH900776 in combination with DNA-damaging agents and antimetabolites. Mol Cancer Ther. 2012; 11:427-438. [PubMed: 22203733]

62. Bartkova J, Horejsi Z, Koed K, Kramer A, Tort F, Zieger K, et al. DNA damage response as a candidate anti-cancer barrier in early human tumorigenesis. Nature. 2005; 434:864-870. [PubMed: 15829956]

63. Gorgoulis VG, Vassiliou LV, Karakaidos P, Zacharatos P, Kotsinas A, Liloglou T, et al. Activation of the DNA damage checkpoint and genomic instability in human precancerous lesions. Nature. 2005; 434:907-913. [PubMed: 15829965]

64. Kawasumi M, Lemos B, Bradner JE, Thibodeau R, Kim YS, Schmidt M, et al. Protection from UV-induced skin carcinogenesis by genetic inhibition of the ataxia telangiectasia and Rad3-related (ATR) kinase. Proc Natl Acad Sci U S A. 2011; 108:13716-13721. [PubMed: 21844338]

65. Montano R, Thompson R, Chung I, Hou H, Khan N, Eastman A. Sensitization of human cancer cells to gemcitabine by the Chk1 inhibitor MK-8776: cell cycle perturbation and impact of administration schedule in vitro and in vivo. BMC Cancer. 2013; 13:604. [PubMed: 24359526]

66. Blackwood E, Epler J, Yen I, Flagella M, O'Brien T, Evangelista M, et al. Combination drug scheduling defines a "window of opportunity" for chemopotentiation of gemcitabine by an orally bioavailable, selective ChK1 inhibitor, GNE-900. Mol Cancer Ther. 2013; 12:1968-1980. [PubMed: 23873850] 


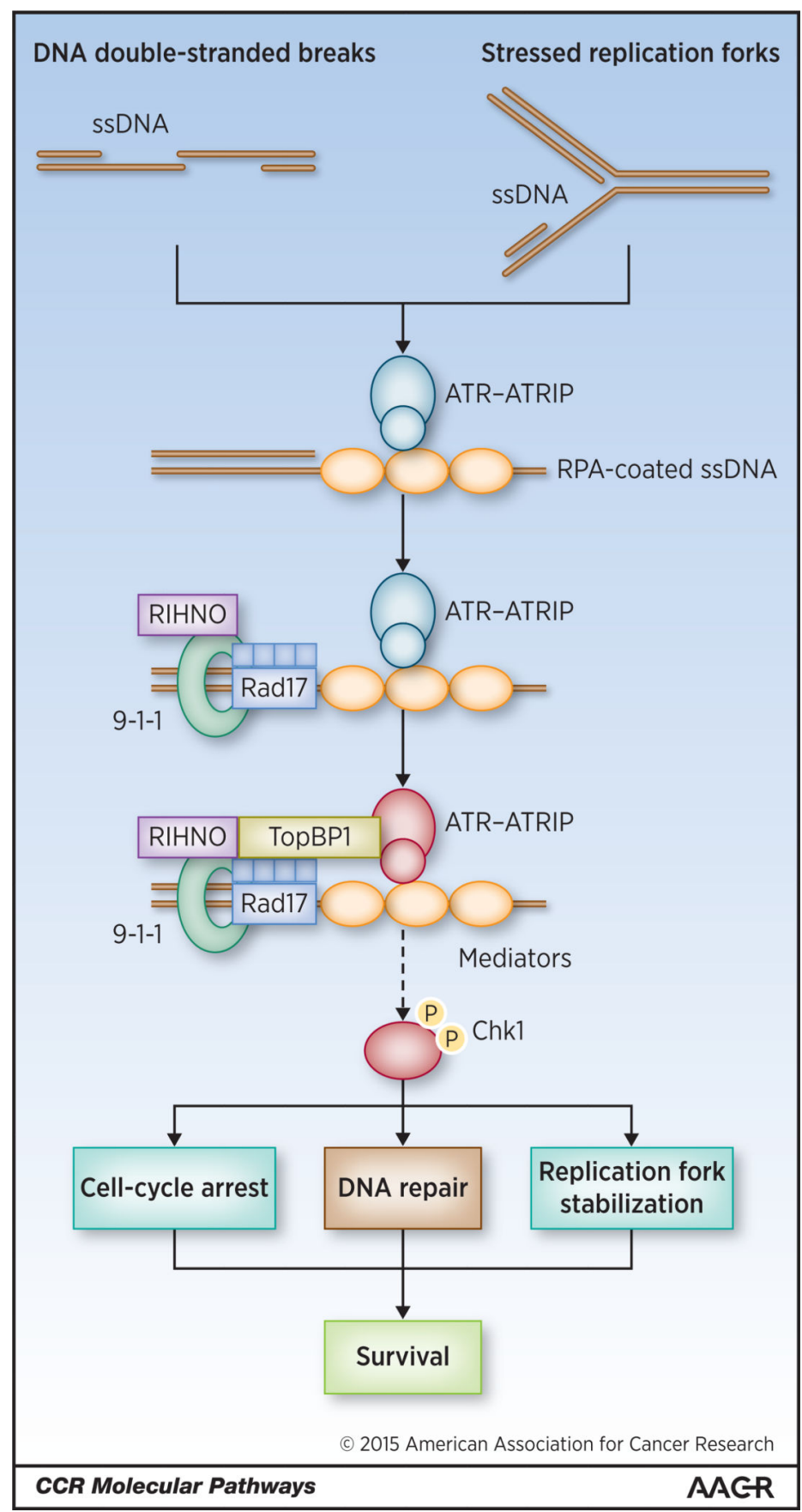

Figure 1.

Activation of the ATR-Chk1 pathway by DNA damage and DNA replication stress. ssDNA, single-stranded DNA. 